\title{
TEORIA CRÍTICA E DOMINAÇÃO NA OBRA DE MOISHE Postone
}

\author{
Sílvio Camargo
}

\begin{abstract}
RESUMO
Buscamos nesse artigo analisar alguns dos aspectos centrais do pensamento de Moishe Postone, em especial algumas ideias de seu livro Time, Labor and Social Domination (1993). Postone é um original historiador e pensador em teoria social crítica cujas pesquisas buscam uma reinterpretação de Karl Marx, em especial do Marx da maturidade, o Marx dos Grundrisse. Na visão de Moishe Postone, o marxismo tradicional tem se mostrado historicamente incapaz de perceber as distinções entre valor e riqueza, assim como entre distribuição e consumo. Além disso, em sua teoria crítica, Postone propõe um entendimento de dominação bastante diferente do marxismo tradicional, trazendo significativos desafios para a teoria social contemporânea.
\end{abstract}

Palavras chave: Marxismo. Teoria Social Crítica. Dominação. Trabalho

\section{CRITICAL THEORY AND DOMINATION IN THE WORK OF MOISHE POSTONE}

\begin{abstract}
In this article we intend to analyze central aspects of Moishe Postone's thinking, in special some ideas of his book Time, Labor and Social Domination (1993). Postone is an original historian and thinker in critical social theory, whose researches undertake to reinterpret Karl Marx, particularly the mature Marx of the Grundrisse. According to Postone, traditional

${ }^{1}$ Professor Doutor do Departamento de Sociologia da Universidade Estadual de Campinas, Brasil. silvioc@unicamp.br

Agradeço as instigantes sugestões dos pareceristas anônimos, embora tenhamos contemplado apenas parcialmente suas sugestões por razões de extensão do artigo.
\end{abstract}


Marxism has proven historically unable to perceive the distinctions between value and wealth as well as distribution and consumption. Moreover, Postone's critical theory proposes an understanding of domination that differs considerably from traditional Marxism's, posing significant challenges for contemporary social theory.

Keywords: Marxism. Critical Social Theory. Domination. Labor

\section{INTRODUÇÃO}

pós noventa anos dos passos iniciais que deram origem ao Instituo de Investigação
Social de Frankfurt, poucos duvidam da importância que teve a chamada Escola de
Frankfurt para o pensamento contemporâneo. ${ }^{2}$ Se o termo é impreciso, o mesmo não pode ser dito daquilo que ela legou para a teoria social contemporânea e mesmo para a teoria sociológica, a formulação de um "modelo" através do qual pensar a história e a sociedade conhecido como Teoria Crítica. Se, por um lado, a chamada teoria crítica da sociedade quase sempre recorre a Karl Marx e a Max Horkheimer como seus fundadores, por outro lado os desdobramentos desta teoria crítica, ao longo desses noventa anos, se multiplicaram por caminhos e contribuições diversas em uma história complexa e ainda viva.

Se Theodor Adorno e Max Horkheimer, Jürgen Habermas, e atualmente Axel Honneth, representam respectivamente as referências centrais daquilo que podemos chamar as três gerações distintas da teoria crítica associada à Escola de Frankfurt, ao mesmo tempo podemos dizer que a teoria crítica ampliou o seu escopo de autores e perspectivas. Em outro lugar (CAMARG0, 2006), defendemos a ideia de que autores tão distintos como Michel Foucault e Fredric Jameson, navegando por referências teóricas bastante externas ao histórico do Instituto de Frankfurt, de algum modo só podem estar situados no campo daquilo que nomeamos como teoria crítica. Por caminhos distintos, a perspectiva oriunda das teses habermasianas igualmente aponta a noção de "reconstrução" (VOIROL, 2012) como fundamental para a própria sobrevivência da teoria crítica, que nesse sentido passa a não ter mais, necessariamente, a dialética como seu elemento fundamental.

A partir de Horkheimer, a ideia de teoria crítica passou a estar diretamente associada aos procedimentos da crítica imanente e da normatividade e aos imperativos de um diagnóstico de época. Em última instância, tais procedimentos são horizontes

\footnotetext{
${ }^{2}$ A expressão Escola de Frankfurt é hoje notoriamente reconhecida como um equívoco conceitual. Continuamos a utilizá-la como forma de facilitar a argumentação. Para nosso entendimento a respeito, ver especialmente; Camargo (2006).
} 
balizadores quanto à relação entre dominação e emancipação na sociedade moderna, onde 0 ideal da emancipação se tornou uma evidência distintiva quanto às pretensões da teoria tradicional (HORKHEIMER, 1983). A teoria crítica jamais teve vida fácil no âmbito da sociologia como campo do saber e disciplina acadêmica, e foi, quanto aos seus representantes frankfurtianos, diversas vezes denunciada como portadora de um déficit normativo no que se refere à primeira geração de frankfurtianos, e déficits sociológicos quanto a todas suas gerações, incluindo Habermas e atualmente Honneth (CAMARG0, 2006).

Uma dentre as razões para isso acreditamos estar justamente na dificuldade quanto a um dos eixos centrais da teoria crítica, a capacidade de empreender um diagnóstico de época que dê conta das transformações pelas quais passa o capitalismo e a sociedade contemporânea, afinal de contas a matéria prima em torno do qual a própria crítica é possível. Um dos problemas negligenciados ou pelo menos até hoje tratado insatisfatoriamente pela teoria crítica é a categoria trabalho e seu efetivo papel na constituição do capitalismo moderno. Pior do que isso, quando nos voltamos para 0 presente, para a passagem do século XX ao XXI, a grande transformação pela qual tem passado a esfera do trabalho humano em todo o mundo, colocando-se como indagação teórica central aos estudiosos da sociedade contemporânea.

Neste início de século XXI, temos percebido algumas tentativas de renovação, reconstrução ou reposicionamento da teoria crítica, não apenas quanto ao círculo de Axel Honneth, mas mediante contribuições teóricas que abordam desde a utopia na pósmodernidade, como Fredric Jameson (2005), até aos fundamentos da teoria do valor de Marx, neste último caso, como a obra do historiador e teórico norte-americano Moishe Postone. Entendemos que sua obra e atuação no debate acerca da relação entre trabalho e dominação é contribuição fundamental para a teoria social inspirada pela herança da obra de Marx.

\section{A CRÍTICA AO MARXISMO TRADICIONAL}

Há exatos vinte anos, Moishe Postone publicava seu trabalho Time, Labor and Social Domination (2003) que apenas agora está em fase de tradução para a língua portuguesa ${ }^{3}$, não obstante ser já bastante conhecido na Europa e nos Estados Unidos. Situando-se, conforme nosso entendimento, no campo de uma teoria social crítica, ao longo desses vinte anos o pensador tem se dedicado ao amadurecimento do que chama um projeto de reconstrução da teoria crítica marxiana (POSTONE, 2003, p. 21). Naquela obra 0 autor já propunha uma reinterpretação das obras de maturidade de Marx. Sua

\footnotetext{
${ }^{3}$ Conforme informações divulgadas pela editora Boitempo, em seu site na internet, em maio de 2013 no link: http://www.boitempo.com/livro_completo.php?isbn=677-85-7577-777-7.
} 
crítica ao marxismo se apresenta como uma crítica imanente ou (auto) crítica, embora não necessariamente evidente. Isto porque sua incisiva denúncia do que chama marxismo tradicional pode parecer para muitos uma crítica externa, afinal o repensar 0 marxismo proposto pelo autor coloca em xeque interpretações consolidadas da obra de Marx, como as interpretações sobre o trabalho abstrato, a teoria do valor e a emancipação.

Para Postone, a emancipação humana é dependente de uma clara compreensão do que é o capitalismo, e tal clareza não tem sido expressa nem nas correntes do que ele chama marxismo tradicional, nem tampouco nos autores pioneiros da teoria crítica da Escola de Frankfurt aos quais ele dedica uma parte considerável de Time, Labor and Social Domination. Falta a ambas as vertentes uma visão adequada do que é o trabalho e o próprio capitalismo para Marx. Para tanto, ele propõe uma reinterpretação da obra madura de Marx, principalmente quanto à recuperação da importância dos Grundrisse $e^{4}$.

0 argumento central por ele desenvolvido é de que o trabalho tem sido interpretado em um sentido trans-histórico, isto é, a crítica ao capitalismo estaria sendo feita primordialmente a partir da categoria trabalho. Em sua visão, ao contrário, o trabalho como Marx o compreende é uma categoria histórica, e em sua obra de maturidade o teórico social alemão tratou de criticar o trabalho como algo específico ao modo de produção capitalista, desvelando como, neste modo de produção, se constitui uma determinada forma também específica de produção de riqueza que é a teoria do valor. Deste modo, o empreendimento de Marx é mostrar como que riqueza e valor se constituem no capitalismo enquanto uma configuração histórica determinada, com características específicas, que evidenciam a existência de um sistema que é acima de tudo uma forma social de dominação, forma social esta que é abstrata e impessoal, e que, portanto, ultrapassa a forma como esta tem sido compreendida pelo marxismo tradicional. 0 que Postone chama de marxismo tradicional não possui uma conotação pejorativa e sua crítica está longe de tonalidades provocativas ou vulgarmente acusatórias e, por outro lado, é representado por uma gama considerável daquilo que Perry Anderson (1989) chamou de marxismo ocidental.

Em última instância, o que define o marxismo tradicional, na visão do autor, é 0 posicionamento quanto à categoria trabalho. Nesse sentido, salta aos olhos não apenas a completa oposição de Postone às leituras ontologizantes da obra de Marx, como ocorre

\footnotetext{
${ }^{4}$ A recuperação desta importância é compartilhada por diversos pensadores contemporâneos. Herbert Marcuse (1978) foi pioneiro desta tarefa, contemporaneamente amplamente difundida pelos chamados teóricos do imaterial, como Negri e Lazzarato (2001) por um lado, e André Gorz (2005), por outro. A apropriação e importância dos Grundrisse tem sido apesar disso um tema bastante polêmico entre marxistas e marxólogos.
} 
com o velho Lukács e com Mészáros, embora tais pensadores não sejam, curiosamente, alvo direto de sua crítica. ${ }^{5}$ Mas, sua crítica também é endereçada ao estruturalismo de Althusser e a Teoria Crítica da Escola de Frankfurt. Entende Postone (2003, p. 43-83) que características da obra do jovem Marx, como a compreensão da luta de classes como núcleo de toda a história, ou a existência de uma lógica no processo histórico, além da ideia de que o trabalho é o centro de todas as relações de sociabilidade nos diferentes momentos da história, possuem como pano de fundo uma trans-historicidade que será superada pelas análises presentes nos Grundrisse e no Capital.

0 chamado marxismo tradicional tende a compreender a dominação exclusivamente como dominação de classes, como uma relação de exploração que tem na apropriação do tempo de trabalho gasto pelo trabalhador o núcleo de uma relação injusta e desigual em prol da apropriação da riqueza por outra classe específica, a burguesia. Para Postone, a dominação capitalista é bem mais do que isso, e para entendê-la é necessário fugir ao entendimento de que a propriedade privada e o mercado são 0 núcleo deste processo. Embora o cerne de seu pensamento só apareça claramente em 1983, quando defende sua tese de doutorado na Universidade Johann Wofgang Goethe de Frankfurt am Main, já no final dos anos 1970 encontramos esboçado 0 caminho da crítica de Postone (1978, p. 745):

A crítica marxiana do capitalismo procede de uma análise das determinações do trabalho social, indicando a possibilidade historicamente emergente de uma nova forma de produção, e não somente de uma crítica da propriedade e outras formas de distribuição.

No entendimento marxista tradicional, a extinção da propriedade privada e a planificação da economia seriam já condições suficientes para a eliminação de relações de dominação tipicamente capitalistas. Enquanto isso, para Postone, a posse dos meios de produção pelo proletariado não elimina o núcleo da dominação capitalista que é a própria produção, isto é, o próprio trabalho industrial moderno como o articulador de relações sociais as quais os homens se submetem. Neste viés tradicional, o que estaria em pauta, na visão do autor, é o modo de distribuição da riqueza e não o próprio modo de produção. Faz-se necessário, portanto, distinguir valor de riqueza, assim como distinguir distribuição de produção.

0 modo de produção diz respeito às próprias características específicas que 0 trabalho expressa no capitalismo, não apenas enquanto trabalho assalariado, mas igualmente quanto ao entendimento de que o trabalho em moldes industriais, com sua

\footnotetext{
${ }^{5}$ Refiro-me aqui especificamente às poucas menções de Postone ao Lukács da "Ontologia", visto que sua análise e crítica de História e Consciência de Classe podem ser encontradas, por exemplo, em: Postone $(2007,2009)$.
} 
forma de divisão, possui em sua própria lógica de existência o germe da dominação social. Deste modo, a crítica de Marx é também uma crítica da modernidade, que visa compreender relações sociais que são abstratas e impessoais, mas nem por isso menos incisivas na configuração da barbárie capitalista. Para Postone, a especificidade do trabalho no capitalismo diz respeito à própria crítica marxiana da mercadoria, isto é, o trabalho abstrato é no capitalismo o elemento de mediação social que constitui 0 conjunto das relações sociais, sendo ele, portanto, o próprio articulador das relações de dominação social.

Decorre das reflexões de Postone uma interpretação das experiências históricas da ex-URSS e do que foi um dia denominado socialismo real, bem como o sentido que poderíamos dar contemporaneamente a ideia de socialismo. Embora não seja um teórico do chamado trabalho imaterial, sua forma de apropriação dos Grundrisse se assemelha em vários aspectos às contemporâneas leituras feitas por André Gorz e Antonio Negri desta obra, em especial quanto ao famoso trecho conhecido como "Fragmento das Máquinas" (MARX, 1989, pp. 690-712). ${ }^{6}$ Ali se coloca a reflexão sobre como a produção da riqueza poderia extrapolar a forma da produção do valor, na medida em que a aplicação da ciência e da técnica na produção, assim como o advento do general intellect, diminuiria crescentemente a importância do gasto de tempo de trabalho humano empregado na produção. A interpretação do texto marxiano incide na reflexão sobre o capitalismo contemporâneo e suas transformações recentes. Nesse aspecto, mesmo os esforços da Teoria Crítica, como os de Friedrich Pollock e Max Horkheimer e depois Jürgen Habermas, se mostraram insuficientes, pois, conforme Postone, ainda lidavam com uma visão tradicional acerca da categoria trabalho.

Não apenas o núcleo de Time, Labor and Social Domination está em uma análise dos textos marxianos de maturidade, mas também a crítica feita nesta obra quanto às limitações dos autores da Escola de Frankfurt estão relacionadas, conforme nosso entendimento da crítica de Postone, às transformações recentes da sociedade capitalista. ${ }^{7}$ Não só as duas primeiras gerações de frankfurtianos se associavam a uma visão tradicional da categoria trabalho, mas a etapa do capitalismo que servia de base para suas análises também se alterou. Na medida em que, a partir da década de 1970, 0 capitalismo ingressa em um novo momento, que contraria diretamente alguns dos diagnósticos de época daqueles autores, se faz necessário para a compreensão do presente uma reinterpretação da própria teoria social crítica, que implica, na ótica de Postone, em uma leitura da obra de Marx que aqueles pensadores não fizeram.

\footnotetext{
${ }^{6}$ Semelhanças e diferenças entre estes intérpretes de Marx, como entre eles e Postone, foram apontadas de forma mais detida em meu livro Trabalho imaterial e produção cultural: a dialética do capitalismo tardio (CAMARG0, 2011).

${ }^{7}$ Reflexões mais específicas sobre tais transformações encontram-se em Postone (1995, 2007, 2012).
} 
0 que está em questão, como pano de fundo, é a compreensão do capitalismo avançado, isto é, em que medida as categorias marxianas são pertinentes para a compreensão de um capitalismo que é diferente daquele do século XIX. É nesse sentido que entra em pauta a problematização quanto ao tempo de trabalho. Em um primeiro momento, apreendemos no autor a constatação de que o capitalismo avançado vive uma forte contradição: de um lado, amadurecem as condições para que a riqueza se constitua não mais como resultante da teoria do valor trabalho, por outro lado, a apropriação do tempo do trabalho alheio e suas correspondentes formas de organização do trabalho continuam inalteradas (POSTONE, 2007, p. 133-193). Não obstante as importantes contribuições para a compreensão das transformações capitalistas dos últimos quarenta anos, como as de Brenner, Arrighi ou Harvey (POSTONE, 2008), se faz necessário uma reconstrução da teoria crítica marxiana que pense a emancipação como algo imanente ao próprio desenvolvimento do capital, isto é, que pense o capitalismo como modo de produção e não de distribuição.

\section{TEMPORALIDADE, RIQUEZA E VALOR}

É lugar comum o entendimento de que para Marx, em toda sua obra, a dominação capitalista é fundamentalmente dominação de classe, a dominação é assim sempre, ao mesmo tempo, a sua manifestação enquanto exploração. 0 proletário é 0 trabalhador assalariado que produz a riqueza capitalista, na forma do valor, e se vê alijado tanto do resultado do seu trabalho quanto do modo pelo qual ele é constituído. 0 sujeito alienado é um apêndice da máquina. Esta dominação de classe e concomitante alienação do proletariado são compreensíveis nos marcos de uma teoria do valor. Haveria, entretanto, no amplo escopo do que vem a ser o marxismo tradicional uma simplificação quanto a esta concepção marxiana de dominação de classes, pois Marx faz referência a um modo de produção, que em sua própria abstração é que tem o sentido de possibilitar a dominação:

$\mathrm{Na}$ análise de Marx, a dominação social no capitalismo não consiste, em um nível mais fundamental, na dominação de pessoas por outras pessoas, mas na dominação de pessoas por uma estrutura social abstrata que estas próprias pessoas constituem. Marx procurou compreender esta forma de dominação estrutural abstrata - a qual está acompanhada, e se estende além, da dominação de classe com suas categorias de mercadoria e capital (POSTONE, 2003, p. 30).

0 que constitui o valor, por seu turno, é o tempo de trabalho humano empregado na produção de mercadorias. Sabe-se, então, que é o tempo de trabalho que mensura 0 valor das mercadorias, constitutivo do trabalho abstrato, e que propicia a formação de 
mais-valia e acumulação de capital. Para Marx, em síntese, é o tempo de trabalho humano despendido na produção de mercadorias o núcleo fundador da própria riqueza capitalista, sob a forma do valor, riqueza esta fundada em um trabalho abstrato.

0 tempo, para Marx, aparece deste modo não só como uma abstração que opera ao nível de uma filosofia da história e através do qual é possível especular sobre o curso da humanidade, ou como no caso de Hegel, do espírito. 0 tempo é uma categoria da crítica da economia política, algo cuja objetividade se manifesta pela práxis humana, formadora de uma história interpretada em moldes materialistas, objetividade esta, concretizada pela ação humana, que é indissociada do próprio conceito de valor. 0 tempo se torna uma categoria também da teoria social crítica e núcleo compreensivo da sociedade capitalista.

Esta constatação decorre da própria crítica marxiana da mercadoria. A grandeza do valor para Marx não resulta do tempo diretamente empregado na produção de uma determinada mercadoria, mas sim do tempo socialmente necessário para esta produção. Assim, é a própria sociedade, enquanto totalidade, que irá consubstanciar a grandeza do valor. A implicação disso é que o tempo também deve ser apreendido como um tempo abstrato, mas que igualmente se coloca como um núcleo compreensivo do tipo de dominação social que caracteriza o capitalismo.

Nas obras de Marx produzidas a partir da metade da década de 1850, começa a se formar o núcleo fundamental de sua crítica da economia política, onde em sua apropriação e crítica de Ricardo e Proudhon configuram-se os elementos que se tornarão centrais em 0 Capital. ${ }^{8}$ Marx primeiramente tenta esclarecer a maneira de constituição do valor das mercadorias, mostrando que tal determinação está constituída pelo trabalho, isto é, será o tempo gasto pelos trabalhadores para a produção de uma mercadoria, enquanto trabalho abstrato, o que elucida a aparente troca de equivalentes no capitalismo?.

0 entendimento de que é o trabalho abstrato a base do valor se tornará algo problemático quando nos confrontamos, por exemplo, com algumas passagens dos Grundrisse que nos informam sobre o tendencial esgotamento do modo de produção industrial. Em diversas passagens dos Grundrisse, Marx sugere que com o avanço das forças produtivas pela grande indústria se desenvolve, no modo de produção capitalista, uma tendência bastante evidente de diminuição do tempo de trabalho humano

\footnotetext{
${ }^{8}$ Sabemos, evidentemente, que a apropriação e crítica da economia política já havia se manifestado na década de 1840, em obras como Miséria da Filosofia e mesmo nos Manuscritos de Paris, mas será com os Grundrisse que se esboça o amadurecimento das argumentações econômicas de Marx.

${ }^{9}$ Não estamos aqui negligenciando o papel cumprido pelo trabalho concreto, mas buscando de forma sumária apontar o sentido da forma valor, visto que é o trabalho abstrato que serve como a mediação social que aponta para uma forma historicamente específica de dominação.
} 
empregado na criação do valor. Sendo o valor, por definição, aquilo que se constitui mediante o tempo de trabalho, teríamos no âmbito do próprio pensamento marxiano, por um lado, um problema quanto à interpretação de sua obra, por outro lado, elementos teóricos que poderiam nos auxiliar na compreensão do capitalismo em seu estágio atual. Conforme Marx (1989, p. 705):

\begin{abstract}
[...] 0 roubo de tempo de trabalho alheio, sobre o qual se funda a riqueza atual, aparece como uma base miserável comparada com este fundamento, recém-desenvolvido, criado pela grande indústria mesma. Tão pronto como o trabalho em sua forma imediata tem deixado de ser a grande fonte da riqueza, o tempo de trabalho deixa, e tem de deixar de ser sua medida e, portanto, o valor de troca (deixa de ser a medida) do valor de uso. 0 sobretrabalho da massa tem deixado de ser condição para 0 desenvolvimento da riqueza social, assim como o não trabalho de uns poucos tem deixado de sê-lo para o desenvolvimento dos poderes gerais do intelecto humano.
\end{abstract}

0 conceito de general intellect que aparece nessa obra madura de Marx se refere a um determinado grau de desenvolvimento do capitalismo em que um conhecimento abstrato, tanto de natureza científica, como não apenas dela, passa a ocupar o papel de principal força produtiva na forma de uma intelectualidade difusa que substitui aquelas formas de trabalho repetitivo exercido pelo proletariado. Estaríamos falando, deste modo, de algo não mais mensurável mesmo nos termos de trabalho abstrato:

0 desenvolvimento do capital fixo aponta para 0 grau em que 0 conhecimento social geral se torna uma força de produção direta, e para 0 grau, portanto, em que as condições do processo da vida social, em si mesma, se colocam sob o controle do 'general intellect' transformando-se de acordo com ele (MARX, 1989, p. 706).

Contudo, lembra-nos Postone que o capital só pode se expandir e se acumular dentro do modo de produção capitalista, pois é só no capitalismo que o trabalho, enquanto força de trabalho, é efetivamente uma mercadoria. Enquanto isso, o valor das mercadorias, cuja determinação está no quantum de trabalho humano nelas consubstanciado, só se valoriza e se torna capital em decorrência desta força de trabalho humano empregado em sua produção, daí a especificidade que possui o trabalho no capitalismo. Trata-se de uma forma histórica específica de produção de riqueza, que não se confunde com esta. Assim nos aponta Postone (1995, p. 60):

Riqueza material é medida pela quantidade de bens produzidos e é uma função de um número de fatores tais como conhecimento, organização social e condições naturais, além do trabalho. Valor é constituído 
unicamente pelo tempo de trabalho humano despendido, de acordo com Marx, e é a forma dominante de riqueza no capitalismo [...]. Enquanto que a riqueza material, quando ele é a forma dominante de riqueza, é mediado por relações sociais visíveis, o valor é uma forma de auto-mediação da riqueza.

0 que a leitura que Postone faz de Marx nos permite é a reflexão acerca de uma situação histórica em que não seria mais o tempo de trabalho o elemento principal do valor, assim a questão a ser colocada é como que o capital continuaria a se valorizar e como se processaria a acumulação. A peculiaridade dos Grundrisse está precisamente em problematizar a circunstância de possível esgotamento do modelo da grande indústria, mas a interpretação do texto marxiano implica grande complexidade, na medida em que tal esgotamento não é tão somente uma decorrência do avanço das forças produtivas, mas dependeria de uma alteração do capitalismo quanto às suas relações de produção, relações estas que não se reduzem ao mercado e a propriedade privada dos meios de produção.

$\mathrm{Na}$ medida em que se desenvolvem as forças produtivas, a tendência geral do capitalismo é produzir riqueza com uma quantidade cada vez menor de trabalho vivo, isto é, de uso do capital variável. 0 tempo de trabalho vivo usado na produção tende a diminuir pelo menos no que se refere à lógica das relações de produção em medida proporcionalmente inversa ao crescimento do capital constante, notadamente da maquinaria. Isso dentro de um modelo de produção industrial, pois em uma produção pós-industrial, o capital fixo (máquinas, equipamentos, imóveis, etc.), também não pode ser considerado nos mesmos moldes em que 0 era na grande indústria. $\mathrm{Na}$ produção pós-industrial (expressão pouco simpática a Postone), ocorre justamente 0 contrário, o acúmulo de riqueza não se daria nem pela apropriação direta do tempo de trabalho alheio, nem pelo somatório de bens materiais instrumentalizados na produção.

Entendemos que em uma releitura dos Grundrisse, tendo como referência as questões historicamente colocadas pela tentativa de reconstrução da teoria crítica proposta por Postone, vemos que o pensamento de Marx deve ser apreendido como uma análise histórica do capitalismo, e, portanto, a categoria trabalho é entendida, como 0 teria sido para Marx, como uma categoria a ser criticada no âmbito do modo de produção capitalista. Isto é, parte-se do capital e do capitalismo para compreender-se 0 trabalho e não o contrário. Pode-se dizer que o trabalho é visto como uma categoria analítica e não ontológica ou mesmo antropológica.

A partir de Postone podemos chegar ao entendimento de que o empreendimento do Marx maduro é fazer a crítica do modo de produção capitalista, apreendendo como 0 âmago deste uma produção de riqueza que se consubstancia como teoria do valor 
trabalho, isto é, o valor surge como a categoria crítica que serve para desmistificar as relações sociais de dominação dentro de um período histórico determinado. Como sabemos, entretanto, para Marx o capitalismo não é o fim da história, pelo contrário, 0 próprio avanço das forças produtivas que entram em contradição com as relações sociais de produção prenunciam a sua crise e a possibilidade de sua superação.

Desta compreensão, decorre que sendo o capitalismo o modo de produção que se identifica à produção do valor, cujo conteúdo social é sempre uma relação de dominação, a questão se tornará bem mais complexa quando a constituição do valor mediante o tempo de trabalho começa a decrescer no âmbito do próprio capitalismo. E aqui não estamos falando da produção da riqueza de uma sociedade, da riqueza capitalista, mas sim do valor que é uma de suas manifestações específicas:

A oposição entre riqueza real e tempo de trabalho será notada. Para enfatizar o que poderia ser um ponto desnecessário, valor para Marx é antes disso uma categoria histórica, antes que natural ou supra-histórica, de riqueza social. Marx escreveu uma "crítica" da economia política, e o valor é para ser compreendido como uma categoria crítica: algo com o qual os fundamentos da forma de riqueza específica ao capitalismo são revelados e ainda o qual - nesta dinâmica - revela a historicidade desta forma. Além de certo estágio histórico, o valor se torna menos e menos adequado como medida da riqueza, isto é, as relações capitalistas de produção se tornam crescentemente anacrônicas nos termos das forças produtivas com as quais elas surgiram (POSTONE, 1978, p. 748).

Enquanto que a riqueza material de uma sociedade pode ser medida pela quantidade de produtos produzidos e se mostra como uma função de diversos fatores como o conhecimento, organização social e mesmo condições naturais, além do próprio valor, este último se refere diretamente ao tempo de trabalho humano que o constitui. Para Marx, conforme passagens do Fragmento das Máquinas mostram claramente, a produção material da riqueza, assentada na criação de valor, terá sua limitação colocada pelo próprio avanço das forças produtivas. 0 argumento marxiano é de que 0 avanço da ciência e da tecnologia implica em uma diminuição do tempo necessário à produção de mercadorias, diga-se, o tempo de trabalho humano despendido em sua produção. 0 trabalho vivo, braçal ou intelectual, vai paulatinamente reduzindo-se às tarefas de controle e vigilância, diminuindo a necessidade da força de trabalho no processo produtivo. A consequência lógica desta diminuição é também a redução do número de horas de trabalho vivo a ser utilizado na produção, que passa a ter no funcionamento das máquinas, e na aplicação da ciência e da técnica, sua principal fonte de produção de riqueza. A teoria do valor encontra então seu próprio limite, na 
medida em que a apropriação do tempo de trabalho alheio, o próprio trabalho assalariado, tende a deixar de existir:

Nessa transformação o que aparece como o pilar fundamental da produção e da riqueza não é nem o trabalho imediato executado pelo homem nem 0 tempo que este trabalha, mas sim a apropriação de sua própria força produtiva geral, sua compreensão da natureza e seu domínio da mesma graças à sua existência como corpo social; numa palavra, o desenvolvimento do indivíduo social (MARX, 1989, p. 705).

Diante tal possibilidade histórica, somos impelidos mais uma vez a pensar sobre como 0 trabalho, enquanto uma forma específica de mediação que representa um sistema abstrato e impessoal de dominação, situa-se frente àquilo que poderia ser entendido por emancipação humana no Marx da maturidade. Desvela-se, mais uma vez, o distanciamento que Postone propõe quanto ao marxismo tradicional, isto é, quanto à necessidade de abandonarmos um conceito de capitalismo como modo de distribuição como o fazem tais marxistas tradicionais, por uma concepção de capitalismo de fato como um modo de produção, como configuração histórica que se identifica ao industrialismo moderno e onde o tempo adquire contornos bastante específicos, caracterizadores da própria modernidade.

A emancipação implicaria, pelo menos, outro olhar quanto ao significado do trabalho para a vida humana. Significaria o fim do trabalho proletário e das formas de divisão e organização que o caracterizam. Embora não seja exatamente a linguagem usada por Postone, a emancipação implica o rompimento da forma específica de racionalidade que caracteriza o trabalho em sentido moderno. Se o trabalho abstrato é a forma por excelência de mediação social no capitalismo, ou na própria modernidade, o seu desaparecimento é condição para o desaparecimento da forma de dominação social também específica que distingue historicamente o capitalismo.

\section{CONSIDERAÇÕES FINAIS}

Como decorrência da extensão e complexidade dos argumentos apresentados por Postone, pudemos apenas esboçar os traços gerais de sua crítica. Também conhecido por sua originalidade nos estudos sobre o antissemitismo (POSTONE; SANTNER, 2003), a crítica deste autor ao valor e ao trabalho guarda alguma semelhança com Robert Kurz (2010). Suas preocupações, entretanto, ainda mantém forte proximidade com a herança de Lukács e Adorno, na medida em que sua análise do Capital incorpora fortemente reflexões sobre a subjetividade, a ideologia e as formas de consciência no capitalismo. Se, por um lado, Postone considera que mesmo os teóricos da primeira geração da Escola de Frankfurt se mantiverem presos a uma visão do trabalho similar a do 
marxismo tradicional, por outro lado, não ignora as contribuições destes quanto à percepção de que a compreensão dos fenômenos culturais é absolutamente indispensável para compreendermos o próprio valor no capitalismo "[...] para dizer em outros termos, para eles teoria crítica da cultura e teoria crítica da sociedade estão intrinsecamente relacionadas, e creio que esta é uma compreensão enormemente valiosa que não deveríamos perder." (LÓPES, 2012, p. 386).

Diferente das perspectivas adotadas por Habermas e, mais recentemente, por Axel Honneth, a forma de apropriação da teoria crítica em Postone se recusa a adotar a perspectiva da intersubjetividade como fundamento epistemológico, como algo que estivesse externo à própria teorização de Marx sobre o capital. No entendimento de Postone, quando o trabalho abstrato aparece como mediação social central do capitalismo, ali também estão sendo consideradas as relações sujeito-sujeito para além da clássica visão sobre as limitações da filosofia da consciência subjacentes à teoria crítica marxiana. Nesse caso, também Habermas, autor longamente analisado no livro de 1993 (2003, p. 226-260), estaria fazendo uma leitura tradicional do trabalho em Marx, privilegiando uma análise do trabalho concreto, em detrimento de uma leitura mais cuidadosa sobre o significado do trabalho abstrato como uma crítica da modernidade.

Mesmo que empreenda uma longa crítica sobre os pensamentos de Daniel Bell e Ernest Mandel como representativos teóricos do capitalismo no pós-segunda guerra (POSTONE, 2007), Moishe Postone está consciente de que suas teorias são insuficientes, quando não equivocadas, para fornecer explicações do capitalismo em sua fase avançada, notadamente suas últimas quatro décadas. Nesse período, apesar das peculiaridades da China e Bangladesh, por exemplo, o declínio do trabalho assalariado como produtor de valor se evidencia como tendência do capitalismo mundial. Diante disso, de nada adiantaria apostarmos mais uma vez na tentativa de encontrar um sujeito revolucionário capaz de empreender uma transformação história frente à própria gravidade da crise do capitalismo (POSTONE, 2012), mas é preciso apostar tanto no aprendizado com a experiência dos acontecimentos em curso no mundo como no abandono de concepções não mais adequadas tanto de capitalismo como de socialismo.

Não temos aqui como analisar o alcance da justeza das críticas de Postone ao que chama marxismo tradicional, afinal quase todo marxismo do século XX acaba por se enquadrar nesta definição. Não temos dúvida quanto ao fato de que o autor já não trabalha mais com a ideia do proletariado revolucionário ou mesmo quanto à possibilidade de um sujeito revolucionário. Conforme ele mesmo diz, sua preocupação está muito mais centrada em fazer com que a teoria nos diga "o que não devemos fazer do que dizer o que devemos fazer" (LÓPES, 2012, p. 401). Embora em diferentes momentos destaque a importância histórica dos chamados novos movimentos sociais (POSTONE, 2004, p. 71), não nos parece que lidemos em sua teoria com algum tipo de 
proposição política clara quanto à emancipação humana. A dimensão normativa da teoria guarda aqui alguma proximidade com os frankfurtianos da primeira geração.

0 sentido dado por Postone ao termo "reconstrução" da teoria crítica é distinto daquele destacado por Habermas (1982), na medida em que a alternativa do teórico norte-americano é de um retorno não dogmático ou ortodoxo ao pensamento de Marx. Este retorno não exclui as contribuições de sociólogos contemporâneos, como Bourdieu (POSTONE, 2003, p. 135), que em alguns momentos teriam grande afinidade com a teoria crítica marxiana, embora Postone se mantenha, conforme nosso entendimento, ancorado na tradição do pensamento dialético. E como outros teóricos dialéticos contemporâneos, Moishe Postone poderia ser nomeado como pessimista por não se pronunciar propositivamente sobre o dever ser, sobre a ação política. Mas, como em outros momentos da história da teoria crítica, nos parece que ele busca dizer que termos clareza sobre o que "não devemos fazer" se constitui como uma condição de possibilidade para qualquer transformação efetiva da história.

\section{REFERÊNCIAS}

ADORNO, Theodor; HORKHEIMER, Max. Dialética do esclarecimento. Rio de Janeiro: Zahar, 1985.

ANDERSON, Perry. Considerações sobre o marxismo ocidental. São Paulo: Brasiliense, 1989 .

CAMARG0, Sílvio. Axel Honneth e o legado da teoria crítica. Revista Política \& Trabalho João Pessoa, n. 24, p. 123-138, 2006.

CAMARGO, Sílvio. Trabalho imaterial e produção cultural: a dialética do capitalismo tardio. São Paulo: Annablume, 2011.

GORZ, André. 0 imaterial. São Paulo: Annablume, 2005.

HABERMAS, Jürgen. Conhecimento e Interesse. Rio de Janeiro: Zahar, 1982.

HEGEL, Georg Wilhelm Friedrich. Fenomenologia del espiritu. México: FCE, 1987.

HORKHEIMER, Max. Teoria tradicional e teoria crítica. São Paulo: Abril, 1983. Coleção 0s Pensadores.

JAMESON, Fredric. Archaelogies of the future. London: Verso, 2005.

KURZ, Robert. Razão sangrenta. São Paulo: Hedra, 2010.

LÓPEZ, Sílvia L. Para una teoría crítica del presente: en conversación con moishe postone sobre las nuevas lecturas de MARX, la crisis y el antisemitismo. Constelaciones Revista de Teoria Crítica, Madrid, v. 4, p. 376-403, Dic. 2012. 
MARCUSE, Herbert. A ideologia da sociedade industrial. Rio de Janeiro: Zahar, 1978.

MARX, Karl. Grundrisse: Foundations of the critique of political economy. Middlesex: Penguin Books, 1989.

NEGRI, Antonio; LAZZARATO, Maurizio. Trabalho imaterial. Rio de Janeiro: DP \& A, 2001.

POLLOCK, Frederich. State capitalism: its possibilities and limitations. In: BRONNER; Stephen; KELLNER, Douglas (Ed.). Critical theory and society. New York: Routledge, 1989. p. 95-118.

POSTONE, Moishe. Crítica, estado e economia. In: RUSH, Fred (Org.). Teoria crítica. São Paulo: Idéias e Letras, 2008. p. 203-233.

POSTONE, Moishe. Critique and historical transformation. Historical Materialism, Leiden, v. 12, n. 3, p. 53-72, 2004.

POSTONE, Moishe. History and heteronomy: critical essays. Tokyo: UTCP: 2009.

POSTONE, Moishe. Marx reloaded: Repensar la teoria critica del capitalismo. In: RIESCO, Alberto; LOPEZ, Jorge Garcia (Ed.). Madrid: Traficantes de Sueños, 2007.

POSTONE, Moishe. Necessity, labor and time: a reinterpretation of the marxian critique of capitalism. Social Research, New York, n. 5, p. 739-788, 1978.

POSTONE, Moishe. Rethinking Marx (in a Post-Marxist World). In: CAMIC, Charles (Ed.). Reclaiming the sociological classics. 0xford: Blackwell, 1995. p. 45-80.

POSTONE, Moishe. Thinking the global crisis. The South Atlatic Quarterly, Durham, v. 111, n. 2, p. 227-249, 2012.

POSTONE, Moishe. Time, labor and social domination. Londres: Cambridge University Press, 2003a.

POSTONE, Moishe; SANTNER, Eric (Ed.). Catastrophe and meaning. Chicago: The University of Chicago Press, 2003b.

VOIROL, Olivier. Teoria crítica e pesquisa social: da dialética à reconstrução. Novos Estudos Cebrap, São Paulo, n. 93, p. 81-99, 2012. 